\title{
The Use of Ethical Dilemma in Mathematics Lesson to Cultivate Students' Ethical Awareness
}

\author{
Mangaratua M. Simanjorang ${ }^{1}$, Pardomuan N.J.M. Sinambela ${ }^{2}$ and Bornok Sinaga ${ }^{3}$ \\ $\left\{\right.$ mangaratuasimanjorang@gmail.com ${ }^{1}$, \\ pardomuannjmsinambela@gmail.com²,bornoksinaga48@gmail.com ${ }^{3}$ \} \\ Mathematics dan Natural Science Faculty, Universitas Negeri Medan, Jl. Willem Iskandar Pasar V, \\ Medan, Indonesia ${ }^{1,2,3}$
}

\begin{abstract}
Indonesian educational community has been focusing on character education recently. Character is usually cultivated upon a set of assumed values that is embraced in one's social environment. This set of values closely related to awareness of ethical values and social relational system in society. Ethical consideration emerges upon the existence of others. The question is if we need to cultivate ethical awareness and consideration then how can we approach this ethical consideration in mathematics education. The researchers team believe that there are valuesin mathematics itself moreover in mathematics education. With this kind of assumption the researchers team are called to find a way to cultivate students' ethical awareness through learning activities. According to some research one possible way for this purpose is the use of ethical dilemma problems. Dilemma occurred in a proposed problem will push a person to consider ethical values before making a decision. Hence, this article aims to describe the possibility of using such ethical dilemma problem in mathematics lecture to cultivate students' ethical awareness. The research described in this article using critical interpretivism paradigm and represented in a narrative inquiry method.
\end{abstract}

Keywords: Ethics, Ethical Dilemma, Narrative Inquiry, Critical Interpretivism.

\section{Introduction}

Character education takes a special attention in Indonesian national education policy recently. Characters may be cultivated through a values embedded social and education environment. Thus the learning environment has an important role in the cultivation of individual characters. For this reason, teachers are expected to be able to integrate character values in learning. This ability needs to be developed since in the teacher's education process. Experiences gained by prospective teachers during their study in university are valuable capital for them that can be reapplied in the practice of their teaching when they become teachers later.

Considering this reason we, the researchers team, are encouraged to offer learning experiences in lectures of a particular subject that allow students to grow their awareness of ethical value considerations. By considering all courses available then we chose to conduct the study in the Selected Topic in Mathematics course. This course was chosen because this course covers topics that will be taught at school. By utilizing the topic in this course in cultivating ethical value awareness, it is expected that students as prospective teachers can 
provide similar experiences to their students in the future. Hence, the question that arises now is how to grow students' ethical awareness through this Selected Topic in Mathematics course. Simanjorang (2016) states that there are two opportunities available in an attempt to integrate ethical values in mathematics learning. First is through uncovering the potential values in mathematics material itself and second is through its pedagogy. We believe that there are values in mathematics. As example consider the importance of universe in mathematics. The result of an operation of numbers depend on the universe where the operation is applied. In Integer 2-3 =-1 while in positive number 2-3 is undefined. In other words, correctness or truth in mathematics depend on it's universe. Different system may come with different truth. In Euclidean geometry it is impossible to have two right angle in one triangle, while in particular Non-Euclidean geometry it is possible for us to have two right angles in a triangle. There is a potential value in this principle. Before deciding whether one's answer is correct we need to consider the universe where the operation is applied. If this principle is applied in real life analogically, before we judge one's opinion we need to consider the assumption one has as the basis for the opinion. Because, different assumption may implicate different consequence hence may result in different judgment. Awareness of the possibility of different truth that related to the assumption used emphasize the need for us to consider first other point of view before making our judgment. There are many other potential value within mathematics.

For this reason, it is necessary to consider the potential values embedded in the mathematical topic that will be taught and what kind of approach can be applied in learning so that ethical values are uncovered in the practice of learning. By paying attention to these two opportunities, thus one way to integrate ethical values in learning is to take advantage of the mathematical problems offered in mathematics learning. Selecting appropriate problems needs to be considered. In this regard we need to consider contexts that close to one's life. The closer the problem offered to the individual's daily experience, the more likely it is that the problem triggers the individual's feelings and imagination (Simanjorang, 2016; Simanjorang, cs., 2017). When problems related to individual experience contain ethical considerations, awareness of ethical values itself will be cultivated. The ethical-dilemma problem is the right example for this purpose.

Settlemaier (2002) states that the use of ethical issues in learning through dilemmas can contribute to the development of social and emotional abilities and critical reflection of individuals. The dilemma encourages individuals to consider choices that both have unpleasant consequences (Settlemaier, 2002). The placement of individuals in this situation encourages him to consider the set of values he adopts before making his choice. If such problems can be formulated in mathematics learning then the mathematics learning class will be enriched with ethical values and students will be able to raise their ethical awareness through mathematics learning classes. The question is how mathematical problems used in learning can involve this ethical dilemma. This is the focus of this study.The problem in this study can be summarized as, "how is the form of the problems that contain ethical dilemma, which can be used in lectures in mathematics selectivity so that students' ethical awareness can be grown?" Hence, the purpose of this study is to develop problems that contain ethical dilemma, which can be used in lectures in mathematics, so that students' ethical awareness can be grown.

\subsection{Ethics}

Ethics is an ancient term that is interpreted differently over time. The history of ethics can be traced back to the ancient Greece. Socrates (William, 2006; Ahbel-Rappe \& Kamtekar, 
2009) asks, "How should someone live? "The efforts to answer this question subsequently led to various concepts about ethics. Aristoteles raised a view on ethics of character that makes an individual a good human being (Crisp, 2004), thus good or bad depends on individual character. Another view came from the utilitarian who viewed that the goodness of an action is based on the consequences or outcomes of the action (Hinman, 2008). If an action ends in a good condition then the action can be seen as a good action. Meanwhile the Kantian views that doing good is the duty of each individual, and that any good action will be recognized anywhere in similar situations (Hinman, 2008). These three views attempt to answer Socrates' question by providing guidance on how to live with others from both the character and action point of view.

In addition to these three views there are other views that are not centered on character or action but rather on relationships between individuals. An individual needs to consider ethical values because of the presence of others around him (Chritchley, 1999). Meanwhile the existence of other people is not determined by any individual so the idea of the existence of others should come from the awareness and understanding of the existence of other individuals. The problem is that it is impossible to totally understand other individuals. What usually happens is that there is one's tendency to reduce the original existence of other individual to an existence that can be absorbed and understood by that one person. Levinas (in Critchley, 1999) said that ethics should be a place for the existence of individuals other than oneself who cannot be reduced to the same as the self. In other words, an individual should respect other individuals as they are, without trying to equate other individuals with oneself or reduce other individuals to the point of conditions that can be absorbed and understood by oneself. Moral awareness requires us 'to respond to' and 'to welcome' the presence of others without trying to reduce and absorb the essence of other people's existence to the point of how we are able to understand them. Welcoming the presence of others in this case means that in relationships with others one needs to respect the differences and uniqueness that other people have. Thus doing good is not the end result of ethics, but the experience of the true existence of others and the recognition of that existence (Simanjorang, 2016). Critchley (1999) asserts that moral awareness does not lead to experience of value but an access to the existence of individuals other than oneself.

\subsection{Values in Mathematics Learning}

One's view of something is based on one's assumptions. Because of this, differences in views about the existence of values in mathematics need not to be debated because they are related to assumptions about mathematics itself. Ernest (1993) explained that mathematics is related to human knowledge, so that mathematics is bound to human culture and is embodied with the values and cultural context that is owned by its creator. Ernest further said that mathematics has rules and values that exist in the rules. When one considers these rules in a mathematical process it can be said that the person thinks mathematically.

Soedjadi (Gijse, 2010) said that students often do not use their mathematical abilities in everyday life but rather their mathematical thinking abilities. This mathematical thinking can be seen as a form of mathematical value itself. Swadener \& Soedjadi (1988) provide a number of examples of values in mathematics characteristics. One is the importance of universe in mathematics. Different universe may determine different results of an operation in mathematics. So the truth in mathematics is very much related to the universe where the operation is applied. 
The analogy of this value in everyday life may help students to appreciate different views and foster the desire to listen to the opinions of others with the consideration that there is a possibility of truth in the views of others. This awareness of the universe in mathematics may also increase awareness of the limits of one's point of view and the environment in which a person is located.

\subsection{Ethical-Dilemma}

Ethical-dilemma is a problem that places a person in two or more choices, each of which has unpleasant consequences (Settlemaier, 2002). Moral considerations itself is not far from the dilemma. The use of the dilemma problem in learning is based on the research of Kohlberg (1996) who developed six stages of moral development. Dilemmas can be presented in the form of stories, films or biographies (Frazer \& Kornhauser, 1986). But the dilemma story is more often suggested to be used as a means to arrive at critical reflection and ethical discussion in the classroom (Settlemaier, 2003). Based on Kohlberg's theory the suitability of the dilemma problem in moral education lies in the ability of the dilemma to lead students to the value clarification stage, where students trace their own values through critical reflection and then compare and discuss them with the values believed by their peers, which if successful will lead to cognitive disequilibrium conditions (Piaget, 1977) which ultimately allows students to learn about ethical values.

\section{Method}

This research was built on the basis of a multi-paradigm view that is criticalinterpretivism, which combines the paradigm of critical-theory and interpretivism. We, researchers team, chose to combine these two paradigms because the characteristics possessed by these two paradigms allow us to explore opportunities for the integration of ethical values into mathematics learning.

This research is intended to bring about changes in mathematics learning, involving consideration of ethical values in itthrough developing ethical dilemma problems that can be used in mathematics lesson, thus it is hoped that mathematics education can bring about a change in society towards a better future. This is in line with the view of critical-theory which tends to increase critical awareness and encourage the construction of a better moral vision of society (Taylor and Medina, 2013). In this case the researcher provides opportunities for students, as prospective teachers, who are the participants of this study to increase their awareness of the values and beliefs that shape their role in learning so far (Taylor, 2008) to further enable them to critically and creatively develop a better learning approach based on critical awareness of these values and beliefs. Critical-theory tend to highlight the problem of social inequality and emphasize positive changes in society (Carspecken, 1996). This is in line with the aim of this study, namely to bring change in society towards a better direction through increasing individual awareness of ethical values through related learning designs.

We use the interpretivism paradigm because in this study we wanted to build understanding based on the context of our own experiences (Taylor, Settelmaier \& Luitel, 2012) in teaching Selected Topics in Mathematics courses to cultivate students' ethical awareness. Through reflection on this experience we may interpret our and other people's thoughts regarding the values and beliefs of each and how we and others are socially related 
(Simanjorang, 2016). Because each individual has a unique interpretation, which is inseparable from the subjectivity of the individual, related to the experience that passes through, the interpretive research allows researchers to utilize their subjectivity in the inquiry process to build understanding (Taylor et al., 2012).

By developing this research on the critical-interpretivism view, the appropriate methodology considered in this study is critical-autoethnography. The critical term in this methodology represents the view of critical-theory brought in this study that emphasizes change towards a better future. While autoethnography was chosen because in this study we wanted to explore how to integrate ethical values through the use of ethical-dilemma in learning, which utilizes the local context.

An understanding of such integration of the ethical values is traced through the life experiences of individuals involved in this study including us the research team ourselves. In other words, the efforts to understand the learning environment conditions that involve ethical values are approached from the researchers' personal experience in relation to the participants involved. This condition is in accordance with the characteristics of autoethnography which tend to link autobiography and personal with culture, social and politics (Elis, 2004). Through reflection on personal experiences we use our views to see how we relate to our cultural environment where we had those personal experiences (Simanjorang, 2016). The cultural environment in this case is the mathematics learning environment. Steps taken in this study are shown in figure 1. Data analysis in this study was conducted at the same time with the data collection because the revisions and changes that needed to be done at each lesson were based on the analysis of the previous lesson.

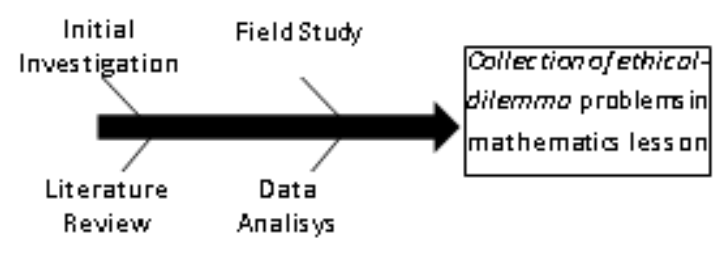

Fig. 1. Fishbone diagram for research steps

This is an on-going research that is being conducted in the Selected Topics in Mathematics course which includes those students who are participating in the course as participants. The research team will act as lecturers and observers. A number of data collection methods such as observation, interviews and student reflection notes will be used in this study, to meet the crystallization quality standards. The crystal has a large but symmetrical surface with a certain angle so it can reflect light beautifully. This crystal metaphor is used to represent how different views in research are valued and used to build deeper, more complex and rich understanding (Richardson, 2005).

\section{Discussion}

This research is still on-going. So far we are doing field study and data analysis steps in the process of developing ethical dilemma problems that may be used in mathematics lesson 
to cultivate students awareness of ethical values. In the first lesson we used the idea of footprint calculator provided by WWF (accessible in https://footprint.wwf.org.uk). This calculator try to calculate our carbon footprint by considering four aspects of our daily life in its calculation such as: 'Food' which covers diet, food waste and buying habits, 'Home' which covers energy type and usage in the house and the presence of energy-saving measures, 'Travel' which covers personal and public transport usage for leisure and work, and flights, and'Stuff' which covers the purchases of consumable items. This calculator than summarizesour average carbon emission also provides suggestion for us to reduce our carbon emission. Although this calculation is based on United Kingdom life style, it can be used as a starting point to trigger our students environmental awareness. By revealing our carbon emission footprint, it helps us to realize what we have done and what we should do for a better environment. Our students responses show the impact of introducing this footprint calculator to their awareness.

Lecturer What do you have in mind after having your carbon footprint calculation result?

Student1 I become more aware about the nature and realize that we need to respect the nature and what it offers to us in order to have a sustainable nature.

Lecturer So what intention do you have now?

Student1 Changing my lifestyle.

Lecturer And how will you do that?

Student2 Reducing plastic usage, for example bringing our own shopping bag instead of using plastic bag from the shop.

Lecturer What else?

Student3 Using our own container instead of bottle drink.

Student1 Reducing our traveling.

Lecturer How can reducing our traveling contribute to the nature?

Student1 It may reduce the production of carbon.

Lecturer What if we are traveling by bike?

Student 1 Oh yes, it's recommended.

Lecturer Ok, what else do you have in your mind?

Student2 Using public transport.

Lecturer How can using public transport contribute to the nature?

Student2 By using public transport we may reduce the amount of vehicle on the road since it may accommodate more people.

This conversation show how the discussion about carbon footprint calculator influenced the students and pushed them to think more about the nature. It is noticeable how they become more aware of the effect of their lifestyle. They also began to creatively and critically think a way for them to contribute to the nature sustainability. By asking the student to reflect on what we have just done in the lesson, they started to realize that it is possible to raise students' awareness of environment and values through the application of mathematics in solving a problem. Hence, we may start to introduce the idea of using problems to cultivate students' awareness of ethical values.

After that we chose statistic to discuss about the problem of plastic waste. In order to do that we started with some facts about plastic waste and problem caused by it. Through this discussion we can see how students' empathy to the animals, which became victims of the irresponsible plastic waste disposal, were raised and they also became worried about the graveness of plastic waste problem to human and nature. After that we asked the students to collect data about plastic usage in their local area. In the discussion about the data they 
collected we raise a question whether it is alright or not to continue using plastic. With their awareness of the graveness of plastic waste problem, they found that this question is a dilemma. Plastic is useful and there are many aspects in daily life that use plastic but it also may harmful to the nature and human. Actually it does not matter whether they choose to continue to use plastic or to stop using it. What is more important is the consideration they had before making that choice. Following conversation reveals students' thought in the discussion about the dilemma.

Lecturer So, what do you think about using plastic, is it still alright to use plastic?

Student1 Using plastic is bad, so we need to stop it. Consequently we need to developan innovation to replace plastic in order to fulfil people needs. As an example there is someone who create an edible bag from seaweed. So, instead of using plastic bag we can use this edible bag.

Lecturer Ok, this is a good idea. What we need daily is a container not the plastic. So, if we have to stop using plastic then we need to consider other material to replace plastic. This edible bags from seaweed is a good example for that. If it is edible then there will be no such plastic waste. Is there any other idea, please?

Student2 We can still use plastic, but instead of throwing it away after one time usage, we can clean it and use it again and again.

Lecturer You mean 'reuse' the plastic, good. In some countries there is a policy to ban the usage of single use plastic. They encourage people to reuse plastic container that they have, this way they can reduce the plastic waste. Ok, any other idea, please?

Student3 In my opinion we can still use plastic, but instead of throwing it away we need to think of recycling it, for example to make toys.

Lecturer Ok, if previous idea is about 'reuse' then now we have the idea of 'recycling'. There are many toys or equipment we have that were created from recycled material including plastic. This is another good way to reduce plastic waste. Ok, any other idea, please? So far we have one person who suggest to stop using plastic while the other two suggest we can still use it with additional consideration.. Have you ever heard about 3Rs?...You haven't... Ok, it's reduce, reuse and recycle. You have raised the idea of reuse and recycle. The one left from $3 \mathrm{Rs}$ is reduce. If we can reduce our usage of plastic product then we can also reduce plastic wastes. For example why do we need to use a straw if we can drink straight away from a glass or bottle, or why do we need more plastic bags if we can use one? By reducing our usage then consequently the amount of plastic waste we produce later will be reduced too.

This conversation reveals different choices taken by the students and their suggestions as a consequence of their choice. All these thoughts are alternative solution they can come with after realizing the problem that come from plastic waste. Getting involved in such a discussion have pushed them to realize and to think about the problem. Being able to propose an alternative solution may be seen as an evidence that they have thought and reflected on the existing problem in other words aware of the problem. In addition to this, by hearing different ideas and choices with different consideration in the discussion they were getting in touch with different point of views. This opportunity may allow them to broaden their view in considering and responding to a particular problem. 


\section{Conclusions}

Dilemma pushed students to reflect deeply on particular choices, because the unpleasant consequence from each choice demand them to think carefully before making a choice. Ethics is about one's awareness and recognition of the existence of other then ethical dilemma will pushed students to be aware and to recognize the existence the other. From previous discussion it can be seen that it is possible to find an ethical-dilemma context that can be used in mathematics learning. The two examples discussed before show two different way to approach this possibility, they are: the application of mathematics concept and the task used in learning mathematics. The first example (carbon footprint) uses mathematics operations to help students being aware of the carbon problem. In other words, by applying mathematics concept students realize that the problem exist. The second example shows how collecting data process and presenting the data reveals the problem to the students. There will be different effect if the data was given to the students to be analysed. By collecting the data, students face and witness the fact and the summarize obtained from analysing and presenting the data enable the students to see the problem clearer. In this case,analysing and representing data have a similar role with the application of mathematical operations in the first example.

\section{References}

[1] Ahbel-Rappe, S., \& Kamtekar, R.: A companion to Socrates,. Willey Blackwell. Sussex. (2009)

[2] Carspecken, P.F.,: Critical ethnography in educational research: a theoretical and practical guide, Routledge, New York. (1996)

[3] Crisp, R., Aristotle: Nicomachean ethics. Cambridge University Press, Cambridge. (2004)

[4] Critchley, S.,: The ethics of deconstruction: Derrida and Levinas. Edinburgh University Press, Edinburgh, $2^{\text {nd }}$ edition. (1999)

[5] Ellis, C.,: The ethnographic I: A methodological novel about autoethnography. AltaMira Press, Walnut Creek. (2004)

[6] Ernest, P.,: The Philosophy of Mathematics Education Falmer Press, London (1993)

[7] Frazer, M.J., \& Kornhauser, A.,: Ethics and social responsibility in science education. Legally Pergamon, Oxford. (1986)

[8] Gijse, A.: Towards a democratic future: Interview with six founding fathers. in R. Sembiring, K. Hoogland \& M. Dolk (Eds.), A Decade of PMRI in Indonesia, Ten Brink. Utrecht (2010)

[9] Hinman, L. M.: Ethics: A pluralistic approach to moral theory,Thomson Wadsworth.United States, 4th edition (2008)

[10] Kohlberg.: Essays on moral development: the psychology of moral development. The nature and validity of moral stages, Harper and Row.San Fransisco, Volume 2 (1984)

[11] Piaget, J.: The moral judgement of the child, Penguin. Harmonsdworth (1977)

[12] Richardson, L.: Writing: A method of inquiry. in N. K. Denzin, and Y. S. Lincoln, (Eds.).,The SAGE handbook of qualitative research (pp. 959-967), Sage, Thousand Oaks, CA, $3^{\text {rd }}$ edition (2005)

[13] Settlemaier, E.: Dilemma stories as a way of addressing ethical issues in the context of science education. Paper presented in the Western Australian Institute for Education Research, Edith Cowan University, Mt. Lawley, Perth, Western Australia (2002)

[14] Settlemaier, E.: Dilemmas with dilemmas: Exploring the suitability of dilemma stories as a way of addressing ethical issues in science education. Paper presented in the Annual Meeting of the National Association for Research in Science Teaching, Philadelphia, PA, 23-26 March, 2003 (2003) [15] Simanjorang, M..: Integrating ethics into mathematics education: A philosophical auto/ethnographic inquiry into Indonesian mathematics education. (Doctoral Thesis), Murdoch University, Murdoch, West Australia, Australia (2016) 
[16] Simanjorang, M., Gultom, S. \& Sinaga, B.: Ethics and 'Pembelajaran Matematika Realistik Indonesia' (PMRI): a critical reflection on mathematics instruction practice. Proceedings of the 1st International Conference on Education Innovation (ICEI 2017),Atlantis Press.volume: 173 (2017) 